\title{
AWE AT NATURAL BEAUTY AS \\ DEFEASIBLE EVIDENCE FOR THE EXISTENCE OF GOD ${ }^{1,2}$
}

\author{
JosÉ EduARdo PorCHER ${ }^{1}$ \\ ${ }^{1}$ https://orcid.org/0000-0002-5654-8396 \\ Universidade Federal de Santa Maria \\ Department of Philosophy \\ Santa Maria, R.S. \\ Brazil \\ jeporcher@gmail.com
}

\section{DANIEL DE LUCA-NORONHA ${ }^{2}$ \\ 2https://orcid.org/0000-0002-4882-5023 \\ Faculdade Jesuita de Filosofia e Teologia \\ Department of Philosophy \\ Belo Horizonte, M.G. \\ Brazil \\ deluca.11@gmail.com}

\begin{abstract}
Article info
CDD: 200.1

Received: 20.06.2021; Revised: 11.10.2021; Accepted: 26.10.2021

https://doi.org/10.1590/0100-6045.2021.V44N4.JD
\end{abstract}

\section{Keywords}

Awe

God

\footnotetext{
1 The authors thank Kelly James Clark for helpful comments to an early draft of this paper.

2 The research that originated this paper was supported by the project "Supporting Constructive Research on the Existence of God in Portuguese-Speaking Latin America" (\#61556) funded by the John Templeton Foundation.
} 
Biophilia

Perception

Natural Beauty

Abstract: In this paper, we present an abductive argument for the existence of God from the experience of awe at natural beauty. If God's creative work is a viable explanation for why we experience awe at natural beauty, and there is no satisfactory naturalistic explanation for the origins of such experiences, then we have defeasible evidence that God exists. To evaluate the argument's tenability, we assess the merits of the two main naturalistic frameworks that can be marshaled to answer the question of why human beings experience awe at natural beauty, Wilson's biophilia hypothesis, and Keltner and Haidt's prototype approach to awe. We show shortcomings of both accounts in explaining the relevant experiences and argue that the reliance of these accounts on an adaptationist reading of our aesthetic appreciation of nature entails a commitment to questionable hidden premises: that affordances themselves can figure in the subject's perceptual experience, and that experiences of awe have adaptive value. We maintain that the argument's "empirical" premise is tenable and conclude with directions for future research regarding the argument's "theological" premise.

\section{Introduction}

Natural beauty and divinity are frequently associated in ordinary religious feeling, but few philosophers have attempted to argue for this connection. Richard Swinburne is a notable exception when he notes that if the universe came into existence without being created by God, there is no reason to suppose that it would be a beautiful universe' (2004, p. 190). Erazim Kohák, for one, remarks that in lived experience, in the radical brackets of the embers and the stars, the presence of God is ... utterly basic, the one theme never absent from all the many configurations of life's 
rhythm' (1987, p. 182). Kohák's plea for a recognition of the deeply rooted and spontaneous character of our sense that divinity is made known in nature is not meant to be an argument from beauty. Alvin Plantinga concurs:

It isn't that one beholds the night sky, notes that it is grand, and concludes that there must be such a person as God ... It is rather that, upon the perception of the night sky or the mountain vista or the tiny flower, these beliefs just arise within us. (2000, p. 175)

Such immediacy suggests that, unlike arguments moving from clearly stated premises to the conclusion that there is a God, something ineluctably phenomenological happens when this belief is elicited by experiences of awe at natural beauty. However, many people and even whole religious traditions don't accept the existence of God based on awe at natural beauty; rather, they regard such awe-experiences as visceral forms of appreciating nature for what it is (Carroll, 1993). And Christian theologian, Thomas F. Torrance holds that, 'nature by itself speaks only ambiguously of God' (1969, p. 59).

But even in people whose reactions of awe do not elicit theistic beliefs, the question of why humans experience awe at natural beauty still stands. As Swinburne (2004, p. 190) observes, even if beauty is something that we project onto nature, this fact still begs the question of why human beings have aesthetic sensibilities that allow them to see nature as beautiful.

Like Swinburne, but unlike Kohák and Plantinga, on the one hand, and Carroll and Torrance, on the other, we believe that there is a properly argumentative way to pursue the link from awe at natural beauty to God's existence, one which has been neglected so far and merits investigation. The 
experience of awe at natural beauty, we argue, provides evidence that God exists. Here is a sketch of the argument's structure:

God's creative work is a viable explanation for why we experience awe at natural beauty.

There is no satisfactory naturalistic explanation for why we experience awe at natural beauty.

Therefore, God exists.

Let us call this the "No Alternatives" Argument for the Existence of God from the Experience of Natural Beauty. As Helen De Cruz and Johan De Smedt (2015, p. 147) point out in their discussion of the argument, failure to come up with an alternative hypothesis to explain a given phenomenon can provide nonempirical evidence in favor of a hypothesis (Dawid et al., 2014). If a theocentric explanation for why we find nature saturated with beauty is viable (premise 1) and there is no alternative naturalistic explanation for this (despite significant efforts to devise one) (premise 2) then this constitutes defeasible evidence for God's existence (conclusion).

Such an argument is not meant to prove the existence of God; rather, it is an argument to the best explanation. To evaluate it, we should examine both the tenability of theocentric and naturalistic explanations for our experiences of awe at natural beauty (Tennant, 1930; Forrest, 1996; De Cruz \& De Smedt 2015, cap. 7). In this paper, we will focus on the latter. In the first section, we will outline the phenomenon of awe and briefly survey empirical studies about its effects on cognition, perception, and spirituality. Following that, in the second and third sections, we will present the two main naturalistic explanations for why we experience awe at natural beauty, due to E. O. Wilson (1984) and Dacher Keltner and Jonathan Haidt (2003), and point 
out internal difficulties with each one. Finally, in the fourth section, we will present philosophical and empirical arguments against naturalistic explanations of awe at natural beauty. We will thus argue that the second premise of the No Alternatives Argument is tenable.

\section{Awe and Natural Beauty}

The sublime, a mixed aesthetic experience of humbleness and elevation in response to a powerful or vast object, has nurtured philosophical and religious discourse for centuries (e.g., Kant 1790/1914; Heschel 1955/2009). As De Cruz \& De Smedt observe:

The term sublime refers to qualities that inspire a sense of awe and wonder with a hint of challenge or danger. Sweeping mountainous landscapes, Niagara Falls, and the Northern Lights are classic examples. Awe (the emotion most associated with the experience of the sublime) has received some attention in aesthetics ... but there is surprisingly little psychological work on its cognitive foundations. (2015, p. 145)

Recently, however, psychology has revived the study of awe. Building on work by Abraham Maslow (1964), Keltner and Haidt (2003) define it in terms of two prototypical features: the perception of vastness and the subsequent need for cognitive accommodation. In short, awe is elicited by stimuli perceived to be greater than the self; this perceived vastness then requires new mental structures to make sense of the experience. 
Awe is a complex emotion that involves different dimensions: cognitive, perceptual, and spiritual. The cognitive dimension refers to the influence of awe on the processing of sensory information. The perceptual dimension refers to the access to perceptual contents marked by phenomenological richness, which captures the agent's attention. And the spiritual dimension refers to an attitude of reverence and belonging concerning the object of experience.

Awe typically involves a break in cognitive expectations when faced with a perceptual experience of phenomena endowed with detail, grandeur, and beauty. On the other hand, awe raises attention and interest, which lead the agent to a contemplative attitude regarding the object of experience. Openness and receptivity, hallmarks of the experience of awe, culminate in a sense of belonging concerning the object of experience. Finally, perceptual experiences that elicit awe lead to accommodation in the cognitive domain, resulting in an expansion of the set of processed information (Rudd et al., 2012).

What are the consequences of awe? According to Keltner and Haidt, 'Awe can transform people and reorient their lives, goals, and values. ... Awe-inducing events may be one of the fastest and most powerful methods of personal change and growth' (2003, p. 312). We outline below four interrelated and indissociable impacts of awe along the three above-mentioned dimensions.

First, awe has social effects. Awe leads people to feel connected with others (Van Cappellen \& Saroglou, 2012), identify with broad group categories such as "humanity" or "inhabitant of the Earth" (Shiota et al., 2007), and behave prosocially (Piff et al, 2015; Rudd et al., 2012).

Second, awe makes the self small. Piff et al.'s (2015) small-self hypothesis posits that the perceived vastness of the object of experience leads to the perception that one's 
self is small relative to the stimuli. Thus, awe facilitates 'a shift in attention toward larger entities and diminishment of the individual self' (Piff et al., 2015, p. 884). Their research on awe, self-categorization, and feelings of smallness indicates that awe can significantly alter the self-concept, eliciting concordance with statements such as 'I feel small or insignificant,' and 'I feel the presence of something greater than myself.'

Third, awe activates religious and spiritual feelings. The duality of feeling both humbled and elevated has been confirmed in self-reports, indicating that participants feel a sense of personal insignificance, a decreased awareness of day-to-day concerns, a sense of something greater than themselves, and a desire for the experience to continue (Shiota et al. 2007). There is some evidence of a close psychological connection between awe and religiosity: empirical studies indicate that the experience of awe increases religious belief (Valdesolo \& Graham, 2014). Sundararajan (2002) has noted that awe frequently brings about a self-reflective attitude: while in awe, we perceive ourselves as experiencing a sense of smallness concerning what is contemplated, mixed with a paradoxical sense of greatness. This may be combined with a kind of joyful willingness to be wholly absorbed by, or surrendered to this experience.

Finally, awe is potentially transformative. Maslow (1962) identified awe as a core moment in the process of change or as the spark to initiate transformation. These cases may occur when intense feelings of awe result in a need to accommodate many of one's mental representations or schemas (Chirico et al., 2016). It may be that the need for accommodation results in changes to the sense of self. In other words, the need for accommodation might make the experience of awe extremely pertinent to an individual to the extent that it can affect her or his identity. Therefore, awe's 
transformative function may trigger a restructuring of individuals' inner world at the most intimate level (Chirico \& Yaden, 2018).

Given the fact that its usual triggers are natural ('the night sky or the mountain vista'), the question we would like to pose is: why does natural beauty elicit awe in human beings? In the following sections, we will present and evaluate the explanatory power of the two main naturalistic hypotheses that may be marshaled to answer this question: Wilson's biophilia hypothesis and Keltner and Haidt's social hypothesis. As we shall see, naturalistic explanations seek to show that the special appreciation that human beings have for natural environments results from adaptive mechanisms, either directly or derivatively. We aim to show that adaptationist accounts of awe at natural beauty are inadequate.

\section{The Biophilia Hypothesis}

The biophilia hypothesis was proposed by Wilson (1984). It asserts the existence of a genetically determined human propensity to connect with nature. Wilson hypothesizes a genetically transmitted preference for the kinds of environment the first homo sapiens lived in, such as the African savannas. These environments provided the natural conditions for the survival of the first human groups. For example, bodies of water such as lakes provided food supplies for humans, such as fish and plants, and a defensive barrier against natural predators. Undergrowth environments offered a better range of vision, protecting humans in the face of threats. Trees with relatively low trunks allowed for climbing, broadening vision, and allowing for escape behavior. Certain kinds of vegetation are a sign of food and so on (Wilson, 1984, p. 110). 
The impact of sensory experience with natural environments is the theme of a range of studies showing that the emotions resulting from exposure to natural landscapes have a restorative effect, in different degrees, on attention, besides providing a decrease in the intensity of negative emotions, the inhibition of unwanted impulses, the reduction of stress, and the expansion of cognitive abilities. These benefits occur in different types of exposure to natural landscapes. They also happen during exposure to photos, videos, and even perceptual experience through windows. Tennessen and Cimprich (1995) show that student dorms with natural views are associated with better performance on attentional measures. Berman et al. (2012) show a correlation between sensory experience in natural environments and working memory enhancement. Hunter et al. (2019) found a reduction in blood cortisol levels and blood pressure from several experiences with natural environments. These studies show that there is a significant difference in response to natural vs. urban environments and that this difference is not culturally relative.

The study by Berto (2005) on the performance of attention elucidates this point. Subjects were separated into two groups. One of the groups was exposed to natural environments and then performed an attention task in which they were to differentiate relevant from irrelevant stimuli; the other group was exposed to urban environments and then performed the same task. Subjects exposed to natural environments were much more successful compared to subjects exposed to urban environments. Also, the reports of subjects in the two groups showed important differences: subjects exposed to natural environments reported feelings of well-being and ease in performing the attention task. In contrast, subjects exposed to urban environments reported anxiety and difficulty in focusing on the task, reporting that 
their experience with urban environments aroused tiredness and stress.

According to Bratman et al. (2010), the mental strain that results from the subjects' exposure to urban environments implies an effort to maintain attention. On the other hand, the positive sensations aroused by exposure to vast natural environments allowed greater fluency in attention tasks. Note that both in natural and urban environments, perceptual attention is overloaded with an excess of sensory information. But what the research above shows is that the feelings of well-being, tranquility, and belonging have positive effects on the attention tasks to which the subjects were submitted after exposure to natural scenarios.

Human sensory contact with nature is conceived here in instrumental terms. From this perspective, perceptually available information in the environment has, so to speak, ecological importance, information that is relevant to the life cycle of the human species. Wilson wants to draw attention to the fact that the perception of the environment is subject to the goals the organism intends to achieve. It is not, therefore, a contemplative sensory experience. Humans then perceive the properties of objects in terms of their motor potential, as affordances of the environment (Gibson, 1979, p. 127). For example, we see a tree as being able to be climbed; a fruit as being able to be peeled, and so on. In general, the natural environment figures as mediating the exploratory activities of humans, allowing some actions and preventing others. Here, perceiving is learning, in a practical sense, how the environment structures the possibilities of an agent's actions.

At first sight, this instrumentalist conception of sensory experience would explain the typical sensations related to awe present in the experience of vastness. Barry (2006) moves in the same direction as Wilson, arguing that positive feelings elicited by experiences with natural environments 
originate in the brain's reward system, which guides our attention to stimuli relevant to survival and reproduction. Feelings of well-being would thus relate to the attention directed to such survival-guaranteeing stimuli. So, both forms of the hypothesis state that feelings constitutive of perceptual experiences with natural environments are associated with adaptive gains presented by natural resources. Wilson reckons that the beauty of the natural setting is a subjective rather than an objective property: 'Is the mind predisposed to life on the savanna, such that beauty in some fashion can be said to lie in the genes of the beholder?' (1984, p. 109). The biophilia hypothesis thus states that sensory experience puts us less in contact with an independent reality that could be the object of a contemplative or aesthetic attitude than with an environment in which we carry out actions aimed at our survival.

In short, we have here an account that focuses on the agents' internal adaptive mechanisms that make them appreciate natural environments. The perceived beauty of this kind of scenery is a by-product of activating survival mechanisms. The agents do not value the scenery because it is beautiful but see the scenery as beautiful because it offers elements which satisfy biological needs. Such a relationship with adaptive mechanisms could explain our tolerance of sensory overload in exposure to natural environments-a tolerance absent in sensory experience with urban environments. Instrumental benefits would have the effect of unburdening the cognitive cost of this exposure. Finally, sensations of well-being would result from this adaptive relationship with natural environments.

However, natural settings that provide adaptive gains are not the only kinds that elicit aesthetic appreciation and reactions of awe. Inhospitable landscapes such as icecovered mountains and sun-blazed deserts, but also sunsets, starry skies, and even images of outer space generate the 
same effects (Gallagher et al., 2015). It is not at all clear what kinds of adaptive gain these natural landscapes could bring about. Certainly not the types of gain countenanced by the biophilia hypothesis, with its focus on savanna-like environments from which human beings first drew their sustenance. As atheist physicist Steven Weinberg quips in Dreams of a Final Theory, 'sometimes nature seems more beautiful than strictly necessary' (2011, p. 250).

Finally, and as we shall argue in section 4, we see a limitation of this kind of naturalistic explanation. Awe elicited by nature entails a diminishment or even an absence of self-interest: subjects in awe are not in a pragmatic or instrumental relationship with the environment, but a contemplative one. But let us first consider another naturalistic approach to understanding awe which may bypass the difficulties with the biophilia hypothesis.

\section{The Social Hypothesis}

We have seen that the biophilia hypothesis accounts for aspects of the natural environment that elicit awe by referring to internal adaptive mechanisms. Keltner and Haidt's (2003) prototype approach to awe exhibits the same tendency but focuses on social contexts. According to Keltner and Haidt awe is primordial since it manifests itself in fixed and stereotyped reactions genetically inherited and evolutionarily modeled, as well as elaborated, given that it is also present, in a derivative way, in other contexts (2003, p. 306). In keeping with the functionalist paradigm, which considers emotions in terms of the role they play in facilitating adaptive behavior (Keltner \& Gross, 1999), the question then is: 'what kind of survival problem does awe address?' (Chirico \& Yaden, 2018, p. 225). 
Keltner and Haidt's approach builds on hypotheses about social cognition. The central idea is that human beings from very early on in ontogeny orient towards their conspecifics. An indication of this sensitivity to others is engagement in dyadic situations in which humans encounter social affordances. Just as perceiving objects as affordances entails opportunities for action, perceiving other humans involves a special type of affordance since it entails face-to-face interaction. As Hobson observes, 'to perceive a smile as a smile is to respond with feeling, in such a way that through the smile one apprehends the emotional state of the other' (2005, p. 190).

Keltner and Haidt theorize that the prototypical case of awe is the emotional reaction between subordinate and leader in human social contexts. Conformity to authority, reinforced by aspects such as prestige and fame, typically arouse feelings of inferiority, surrender, and belonging typical of awe. Such conformity would have enabled the internal cohesion of the first human groups, marked by hierarchical relationships and specific social functions. The feelings of well-being related to this conformity to others would represent an undeniable social gain. Awe would thus derive from adaptive mechanisms expressed in the hierarchy among agents of the same social group. According to this view, awe acts as a primordial response to displays of power by gathering people around a central dominant figure, reinforcing their shared social identity. As Chirico \& Yaden observe:

From the subordinate's perspective, the reaction of fear and respect combined with wonder in front of someone more powerful would strengthen and maintain social hierarchies. The negative or fearful aspects of awe are particularly relevant to this perspective, 
though this perspective has been somewhat neglected in the research literature ... Specifically, this view of awe depends on circumstances in which there is a power gradient in the group. (2018, p. 225)

Keltner and Haidt go on to hypothesize that awe became generalized to any form of vastness, including panoramic vistas and sweeping scenery. That is, social triggers would have come before natural and other aesthetically related ones. Contrary to the biophilia hypothesis, Keltner and Haidt's approach suggests that awe present in sensory experiences with vast environments would thus derive from a social-adaptive mechanism. Its manifestation in sensory experiences with natural environments or any other phenomenon endowed with grandeur and power would be a manifestation derived from social anchoring.

Note that the social hypothesis is more comprehensive than the biophilia hypothesis. It would countenance other phenomena in addition to environments that provide sustenance for human beings. However, both approaches understand awe only as it relates to adaptive mechanisms. Whereas according to the biophilia hypothesis humans appreciate natural environments because they provide conditions for sustenance-sensory content then amounting to a set of natural affordances-according to the social hypothesis, humans appreciate others who are in a position of power in order to gain social benefit. In this case, the perception of another as hierarchically superior gives rise to a series of adaptive behaviors. Because it has the advantage of reinforcing the ties of belonging to the group of which the percipient is part, the perception of the other whose actions exhibit prestige and authority would involve a case of social affordance. Note that in both cases the external phenomena 
inducing this emotion matter less than actions that generate some eventual adaptive benefit.

Note that the prototype approach to awe fails to explain why not just powerful individuals but also divergent stimuli such as 'the night sky or the mountain vista or the tiny flower' or, for that matter, a mathematical proof, or a choral work by Arvo Pärt elicit this emotion (De Cruz \& De Smedt, 2015, p. 147). Indeed, Keltner and Haidt's approach flies in the face of empirical research that shows that other human beings are not at all the primary elicitors of awe. ${ }^{3}$ CaldwellHarris et al. (2011) found that the three key elicitors of awe in Christians, Buddhists, and atheists are nature (54 percent), science (30 percent), and art, especially music (12 percent). Shiota et al. (2007) found that the most common elicitors of awe are nature (27 percent) and art, especially music (20 percent).

Furthermore, awe can be induced through proximity to physical vastness. For example, studies have used stimuli such as groves of tall trees to elicit experiences of awe in participants (Piff et al., 2015). Virtual reality can also be used to simulate proximity to vastness (Chirico et al., 2016). For example, Chirico et al. (2021) have gauged participants' emotional responses before and after being exposed to

\footnotetext{
${ }^{3}$ Note that the statement that 'other human beings are not at all the primary elicitors of awe 'is not intended to take aim at the social hypothesis as a whole, but only in relation to the character derived from awe attributed by this hypothesis to cases of perception of vastness. With regard to the evolutionary character of the social hypothesis, we agree that awe can manifest itself in social contexts and, therefore, that it can have adaptive value. However, contrary to the hypothesis, we assert the specificity of awe in situations of vast perceptual experience. As we argue below, in these situations, awe is not derived from the adaptive value resulting from its manifestation in hierarchical social contexts.
} 
Vincent Van Gogh's The Starry Night and a photorealistic version of the actual place depicted in the painting (SaintRémy-de-Provence, in Southern France), finding that the nature-based format induced higher intensity emotional responses than the art-based format. Thus, the paradigm example of an awe-inducing stimulus is a panoramic scene of natural beauty, contrary to Keltner and Haidt's approach.

Finally, in the social hypothesis, the experience of the other as something that would involve a set of social affordances does not include the vastness of experiences with natural environments. Thus, this experience would lack the specifics and consequences that occur when faced with the relevant stimulus. For this reason, the extension intended by Keltner and Haidt from social relations to natural environments is far from clear. Furthermore, as we shall argue in the next section, the phenomenology of sensations present in awe, devoid of self-interest, cannot be accounted for by the social hypothesis, either.

\section{Problems for Naturalistic Explanations of Awe}

We question the explanatory success of adaptationist accounts of the origins of awe at natural beauty on the grounds of internal cohesion. Such accounts do not do justice to (1) the phenomenological content of the experience of natural vastness, and to (2) the sensations present in awe at natural beauty, which do not have an evident adaptive value.

Consider a vast, sweeping seascape as in Caspar David Friedrich's The Monk by the Sea (Fig. 1) or the display of light and color after the sun sets (Fig. 2). A sensory range characterizes the agent's visual field, endowed with different physical phenomena, a profusion of details, colors, and so on. This astonishing variety of perceptual information 
arouses the agent's attention. In turn, the detailing of this perceptual information exceeds the agents' conceptual repertoire.

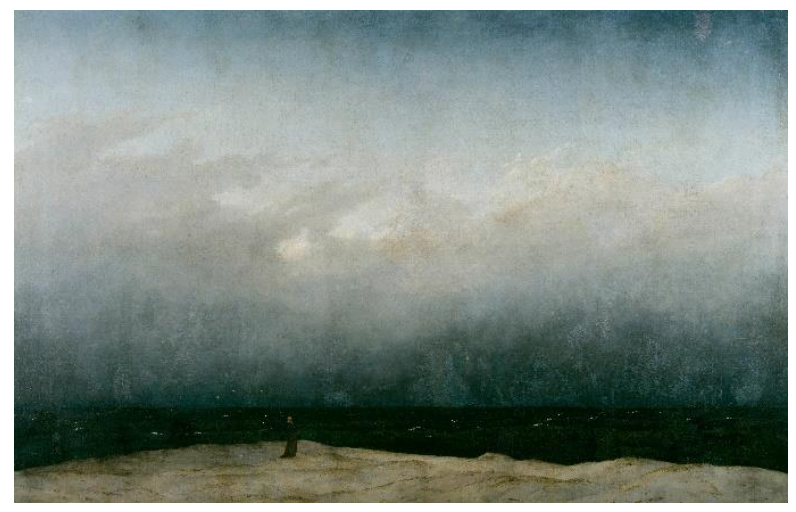

[Fig. 1] Caspar David Friedrich, The Monk by the Sea (1808-10).

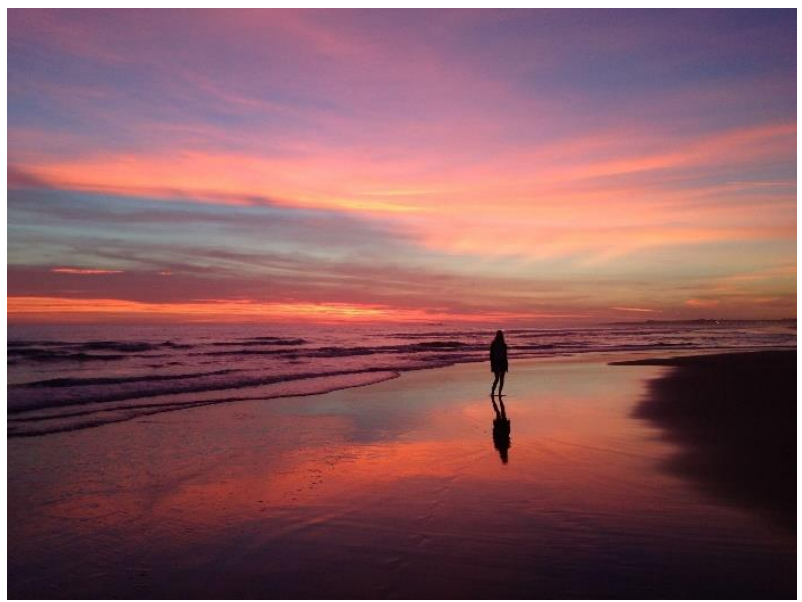

[Fig. 2] Twilight by the ocean. Photo by Christin Ruhnau.

Manuscrito - Rev. Int. Fil. Campinas, v. 44, n. 4, pp. 489-517, Oct.-Dec. 2021. 
The possession of concepts requires the ability to use them in thinking, particularly in inferential reasoning (Evans 1982, p. 210), i.e., the ability to construct different judgments with them. Suppose agents having experiences of vastness possess concepts for every kind of phenomenon they perceive. With these concepts, they describe their experience. Even so, it is likely that they will be able to distinguish phenomenal aspects by perceptual attention that they will not retain in long-term memory, given the finegrained character of these distinctions (Abath, 2005). That means that they are unlikely to recognize the same aspects in different, particularly future, situations. So although they can discriminate different shades of color, shapes, and so on, they will not recognize the same distinctions on other occasions, despite the same aspects being present (Kelly, 2001). Hence, they do not have the relevant concepts. As Gareth Evans (1982, p. 229) remarked, it is difficult to understand the proposal that we have as many color concepts as there are shades of color that we can sensibly discriminate.

The fineness of grain of perceptual content characterizes its non-conceptual character (Tye, 2006). At least part of the perceptual content present in experiences of vastness goes beyond the agent's conceptual repertoire. As such, this finegrained content of sensory experience is therefore not capable of being utilized in inferential thinking. Nor is such content stored in long-term memory so one could recruit it into recognition tasks in other contexts. Note that the perceptual content that exceeds the agent's conceptual resources can explain the impact of the experience of vastness, which is otherwise not present in ordinary sensory experiences. As Christopher Peacocke observes:

If you are looking at a range of mountains, it may be correct to say that you see some of 
them as rounded, some as jagged. But the content of your visual experience in respect of the shape of the mountains is far more specific than that description indicates. The description involving the concepts round and jagged would cover many different fine-grained contents which your experience could have, contents which are discriminably different from one another. (1992, p. 111)

We maintain that the fineness of grain of the perceptual content present in experiences of vastness is responsible for arousing the typical reactions of awe. It is precisely this phenomenological richness that can explain why, in this type of experience, agents report having thoughts of the presence of something greater than themselves, a lack of concern with themselves and with ordinary tasks, and a more intense connection with humanity and the world. It may also explain the expansion of cognition brought about by awe (Rudd et al., 2012).

As we have seen, in naturalistic explanations of the origins of awe our appreciation for natural environments derives from the adaptive value of its elements, such as groves of trees, bodies of water, and so on. For example, the experience of a Japanese maple tree (Fig. 3) entails perceiving the relevant affordances for the biological satisfaction of the needs of human beings. In this case, it is about perceiving an object that can be climbed, as protection against some external threat, and so on. Thus, the perception of this object is subject to the ends that the percipient wants to achieve. Given the adaptive value of the perceptual content of phenomena present in natural environments, this type of experience would thus awaken reactions of awe. However, there are philosophical and empirical reasons to believe that the processing of the adaptive relevance of physical 
phenomena does not figure in the phenomenological content of conscious sensory experience.

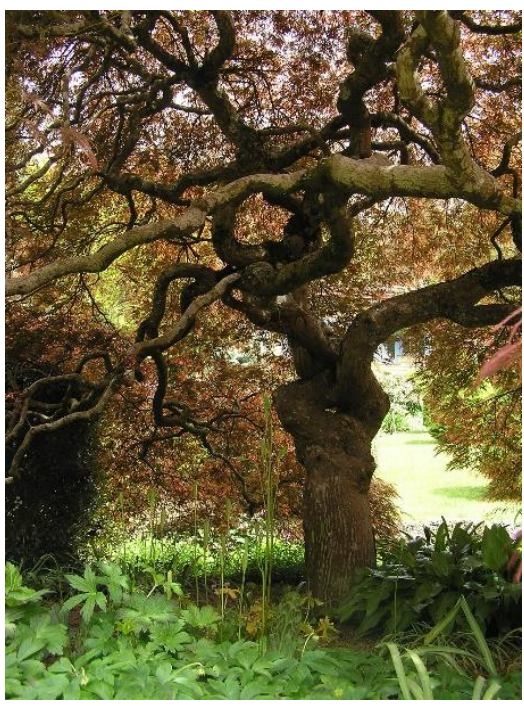

[Fig. 3] Japanese maple tree (Acer palmatum). Photo by Gwenda Lyons.

First, the assertion that affordances themselves can figure in the subject's visual field is questionable. Affordances are not objective properties that are present in the world independent of agents. They partly depend on the agential capacities of individuals belonging to a particular species. Furthermore, there may be variations between individuals of the same species. Depending on each individual's level of expertise, they may not access the same affordances from the same relevant objects. But this does not mean, of course, that they see different objects. So much so that, despite these differences, they can coordinate actions around the same perceived object. On the other hand, if we were to say that objects are perceived as affordances, it would be difficult to 
show how human beings, having different skills or expertise, see the same object in a way that allows the coordination of actions. As Noë (2004) observes, the assertion that affordances can appear in the agents' visual field involves the risk of inflating the perceptual content, or even making it mysterious, endowing it with non-phenomenal properties.

Second, research by Milner and Goodale (1999) and Sheth and Young (2016) provides evidence of two distinct paths through which visual information goes, the ventral stream and the dorsal stream. The ventral stream processes information about the phenomenon's identity and provides an allocentric location of objects in the visual field. The perceptual information in this system is available to consciousness. The ventral stream ensures that some of the perceptual content that exceeds our conceptual capabilities is available to the agent's awareness throughout the sensory experience.

We can also observe this in research showing that perceptual attention is a necessary and sufficient condition of consciousness (Carruthers, 2015, pp. 1-18; Prinz, 2012, pp. 183-188). In effect, perceptual information becomes unavailable to consciousness if subjects get distracted and shift the focus of attention. On the other hand, the dorsal stream processes information about objects according to their motor potential and relevance to the agent's action. This processing, however, occurs in a subpersonal way. If its content is not available to consciousness, the phenomenology of sensory experience cannot include affordances of objects. Prinz summarizes this point:

$[T]$ here is no constitutive link between visual consciousness and the processes that control action. Seeing and acting are dissociable. This might be taken to imply that consciousness has little to do with action; perhaps theories of 
consciousness can be developed without emphasis on or even mention of how behavior is produced. (2012, p. 189)

It follows that awe caused by vast perceptual content bears no relation to the instrumental or adaptive value of that content. ${ }^{4}$ While we do not deny that the natural phenomena present in perceptual experiences may have adaptive value, we do deny that such value is a part of the sensory content of conscious experience. Given that it locates the adaptive value in conscious perceptual experience, adaptationist accounts fail to explain why natural beauty elicits awe. As far as sensory experience is concerned, awe does not seem to be caused by anything other than the phenomenological richness of the content experienced. Furthermore, instrumental aspects of the objects that guide actions with adaptive purpose are not available to the agent's consciousness.

Finally, the sensations constitutive of awe are the converse of those countenanced by naturalistic explanations. Although the phenomenology of awe includes connection with the environment, the feelings that emerge include lack of concern for oneself, detachment from mundane things, among others—all without apparent adaptive value. These

4 It is true that the biophilia hypothesis, situated within the framework of the theory of evolution, could affirm that the instrumental value resulting from human beings' contact with nature is not related to conscious experience. Thus, the statement that the perception of affordances is not available to the awareness of the percipient subject would not be a valid criticism of the biophilia hypothesis. Even so, however, the conscious awareness of vast natural environments that prototypically induces awe and wonder regardless of any instrumental or adaptive value would remain unexplained. 
feelings do not point to an instrumental but to a contemplative or aesthetic relationship with the environment. Adaptationist explanatory accounts privileging the satisfaction of the agent's or the group's needs ignore the disinterested, self-transcendent aspects of experiences of awe at natural beauty.

\section{Conclusion}

In the previous discussion, we hope to have shown the limitations of the best naturalistic explanatory frameworks for the origins of awe at natural beauty. Both the biophilia and the social hypotheses fall short for reasons specific to each approach. The biophilia hypothesis fails to explain why we are attracted not only to the savanna-like environments that provided sustenance to the first homo sapiens but also to icy landscapes, sun-blazed deserts, and natural phenomena that provide no subsistence gains, such as sunsets, the view of the night sky, etc. The social hypothesis fails to explain why not only natural landscapes, but also science, music, and pictorial art elicit awe in demonstrably greater frequency than powerful people. Beyond these internal issues, as we have argued, the reliance of these accounts on an adaptationist reading of our aesthetic appreciation of nature entails a commitment to a questionable hidden premise which we have exposed, namely, that affordances themselves can figure in the subject's perceptual experience. Furthermore, it entails a commitment to the supposed survival benefits of experiences that, in and of themselves, have no apparent adaptive value.

If there is no satisfactory naturalistic explanation for why we experience awe at natural beauty, the second premise of the "No Alternatives" Argument for the Existence of God 
is vindicated. As we pointed out in the introduction, even if the relationship between awe and religiosity is experiential rather than the result of a premise-conclusion style argument, we can develop an abductive argument using such experiences as a premise. The question remains as to how plausible the argument's other premise is, namely, that God's creative work is a viable explanation for why we experience awe at natural beauty. De Cruz and De Smedt (2015, p. 147151) suggest two ways to defend a theocentric account of natural beauty. A first way would explore why God would design humans such that they have aesthetic experiences. For example, Polkinghorne (1998, p. 82) argues that enjoying the natural world provides ineffable knowledge of God's artistic intentions (De Smedt \& De Cruz, 2013). A second way would regard aesthetic experience as a subspecies of religious experience. For example, Heschel saw awe at natural beauty (not only vast things but also things such as Plantinga's 'tiny flower') as an essential element of religious sensibility. For Heschel, awe 'is more than an emotion; it is a way of understanding' ([1955] 2009, p. 74). Although it has not been the aim of this paper to argue how theism explains aesthetic experience, we maintain that if there is a viable way to do it, then we have defeasible evidence for the existence of God.

\section{References}

ABATH, A. "Nonconceptual content, fineness of grain and recognitional capacities“. Abstracta 1(2), pp.193-206, 2005.

BARRY, A. "Perceptual aesthetics: Transcendent emotion, neurological image". Visual Communication Quarterly, 13(3), 134-151, 2006. 
BERMAN, M.G., KROSS, E., KRPAN, K.M., ASKREN, M.K., BURON, A., DELDIN, P.J., KAPLAN, S., SHERDELL, L., GOTLIB, I.H., JONIDES, J. "Interacting with nature improves cognition and affect for individuals with depression". Journal of Affective Disorders, 140(3), pp. 300-5, 2012.

BERTO, R. "Exposure to restorative environments helps restore attentional capacity". Journal of Environmental Psychology, 25, pp. 249-259, 2005.

BRATMAN, G. N., HAMILTON, J. P., DAILY, G. C. “The impacts of nature experience on human cognitive function and mental health". Annals of the New York Academy of Sciences, 1249, pp. 118-136, 2012.

CALDWELL-HARRIS, C. L., WILSON, A. L., LoTEMPIO, E., BEIT-HALLAHMI, B. "Exploring the atheist personality: Well-being, awe, and magical thinking in atheists, Buddhists, and Christians". Mental Health, Religion \& Culture 14, pp. 659-672, 2011.

CARROLL, N. "On being moved by nature: Between religion and natural history". In S. Kemal and I. Gaskell (eds.) (1993), pp. 224-266.

CARRUTHERS, P. The Centered Mind. What the Science of Working Memory Shows Us About the Nature of Human Thought. Oxford: Oxford University Press, 2015.

CHIRICO, A., YADEN, D.B. "Awe: A Self-Transcendent and Sometimes Transformative Emotion". In H. Lench (ed.) (2018), pp. 221-233.

CHIRICO, A., YADEN, D.B., RIVA, G., GAGGIOLI, A. "The Potential of Virtual Reality for the Investigation of Awe". Frontiers in Psychology, 7, 1766, 2016. 
CHIRICO, A., CLEWIS, R.R., YADEN, D.B., GAGGIOLI, A. "Nature versus art as elicitors of the sublime: A virtual reality study". PLOS ONE 16(3), e0233628, 2021.

DAWID, R., HARTMANN, S., SPRENGER, J. "The no alternatives argument". British Journal for the Philosophy of Science 61, pp. 213-234, 2014.

De CRUZ, H., De SMEDT, J. A Natural History of Natural Theology. Cambridge, Mass.: MIT Press, 2015.

De SMEDT, J., De CRUZ, H. “Delighting in natural beauty: Joint attention and the phenomenology of nature aesthetics". European Journal for Pbilosophy of Religion, 5, pp. 167-186, 2013.

EILAN, N., HOERL, C. McCORMACK, T., ROESSLER, J. Joint Attention: Communication and Other Minds: Issues in philosophy and psychology. Oxford: Oxford University Press, 2005.

EVANS, G. The Varieties of Reference. Oxford: Oxford University Press, 1982.

FORREST, P. God Without the Supernatural: A Defense of Scientific Theism. Ithaca, New York: Cornell University Press, 1996.

GALLAGHER, S., REINERMAN-JONES, L. JANZ, B., BOCKELMAN, P., TREMPLER, J. A Neurophenomenology of Awe: Towards a Non-Reductionist Cognitive Science. London: Palgrave Macmillan, 2015.

GENDLER, T., HAWTHORNE, J. Perceptual Experience. Oxford: Oxford University Press, 2005.

GIBSON, J.J. The Ecological Approach to Visual Perception. Boston: Houghton Mifflin Harcourt, 1979. 
HESCHEL, A.J. God in Search of Man: A Philosophy of Judaism. London: Souvenir, 2009.

HOBSON, R.P. "What Puts the Jointness into Joint Attention?" In N. Eilan, C. Hoerl, T. McCormack, \& J. Roessler (eds.) (2005), pp. 185-204.

HUNTER, M., GILLESPIE, B., CHEN, S. "Urban Nature Experiences Reduce Stress in the Context of Daily Life Based on Salivary Biomarkers". Frontiers in Psychology, 10, 722, 2019.

KANT, I. The Critique of Judgment. Transl. by J.H. Bernard, New York: Macmillan, 1914.

KELLY, S. "Demonstrative Concepts and Experience". Philosophical Review 110, pp. 397-420, 2001.

KEMAL, S., GASKELL, I. Landscape, Natural Beauty, and the Arts. Cambridge: Cambridge University Press, 1993.

KELTNER, D., GROSS, J.J. "Functional accounts of emotions". Cognition and Emotion, 13, pp. 467-480, 1999.

KELTNER, D., HAIDT, J. "Approaching awe: a moral, spiritual, and aesthetic emotion". Cognition and Emotion, 17(2), pp. 297-314, 2003.

KOHÁK, E. The Embers and the Stars: A Philosophical Inquiry into the Moral Sense of Nature. Chicago: Chicago University Press, 1987.

LENCH, H. The Function of Emotions. Cham: Springer, 2018.

MASLOW, A.H. "Lessons from the peak-experiences". Journal of Humanistic Psychology, 2, pp. 9-18, 1962.

MASLOW, A.H. Religions, Values, and Peak Experiences. Columbus: Ohio State University Press, 1964. 
MILNER, A., GOODALE, M. The Visual Brain in Action. Oxford, 1999.

NOË, A. Action in Perception. Cambridge, Mass.: MIT Press, 2004.

PEACOCKE, C. "Does Perception Have a Nonconceptual Content?" The Journal of Philosophy, 98, pp. 239-264, 2001.

PIFF, P.K., DIETZE, P., FEINBERG, M., STANCATO, D.M., KELTNER, D. "Awe, the small self, and prosocial behavior". Journal of Personality and Social Psychology, 108(6), pp. 883-899, 2015.

PLANTIGA, A. Warranted Christian Belief. Oxford: Oxford University Press, 2000.

POLKINGHORNE, J. Science and Theology: An Introduction. Minneapolis: Fortress Press, 1998.

PRINZ, J. The Conscious Brain. How Attention Engenders Experience. Oxford: Oxford University Press, 2012.

RUDD, M., VOHS, K.D., AAKER, J. "Awe expands people's perception of time, alters decision making, and enhances well-being". Psychological Science, 23, pp. 1130-1136, 2012.

SHETH, B., YOUNG, R. "Two Visual Pathways in Primates Based on Sampling of Space: Exploitation and Exploration of Visual Information". Frontiers in Integrative Neuroscience, 10, 37, 2016.

SHIOTA, M., KELTNER, D., MOSSMAN, A. "The nature of awe: elicitors, appraisals, and effects on selfconcept". Cognition and Emotion, 21(5), pp. 944-963, 2007. 
SUNDARARAJAN, L. "Religious awe: Potential contributions of negative theology to psychology, "positive" or otherwise". Journal of Theoretical and Philosophical Psychology 22, 174-197, 2002.

SWINBURNE, R. The Existence of God. Oxford: Oxford University Press, 2004.

TENNANT, F.R. Philosophical Theology: The World, the Soul, and God, vol. 2. Cambridge: Cambridge University Press, 1930.

TENNESSEN, C.M., CIMPRICH, B. "Views to nature: Effects on attention". Journal of Environmental Psychology, 15(1), pp. 77-85, 1995.

TORRANCE, T.F. Space, Time and Incarnation. Oxford: Oxford University Press, 1969.

TYE, M. "Nonconceptual Content, Richness, and Fineness of Grain". In T. Gendler \& J. Hawthorne (eds.) (2005), pp. 504-530.

VALDESOLO, P., GRAHAM, J. "Awe, uncertainty, and agency detection". Psychological Science 25, pp. 170-178, 2014.

Van CAPPELLEN, P., SAROGLOU, V. "Awe activates religious and spiritual feelings and behavioral intentions". Psychology of Religion and Spirituality, 4(3), pp. 223-236, 2012.

WEINBERG, S. Dreams of a Final Theory. New York: Knopf Doubleday, 2011.

WILSON, E.O. Biophilia. Cambridge, Mass.: Harvard University Press, 1984.

$(c c)$ EY 